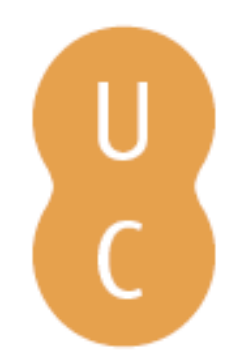

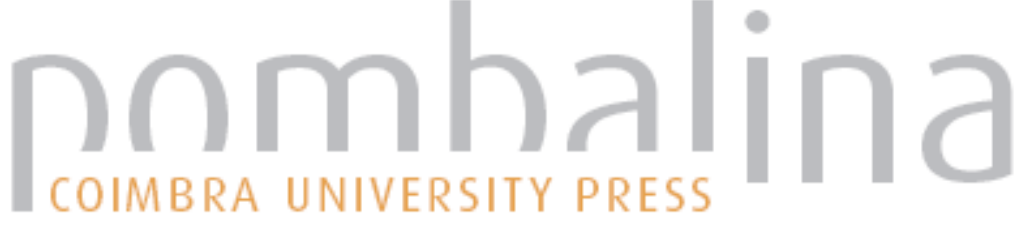

\section{Bons selvagens e monstros malditos em Heródoto e Eurípides}

Autor(es): Soares, Carmen

Publicado por: Imprensa da Universidade de Coimbra

URL

persistente: URI:http://hdl.handle.net/10316.2/32050

DOI: $\quad$ DOI:http://dx.doi.org/10.14195/978-989-26-0499-2_6

Accessed : $\quad$ 26-Apr-2023 13:59:07

A navegação consulta e descarregamento dos títulos inseridos nas Bibliotecas Digitais UC Digitalis, UC Pombalina e UC Impactum, pressupõem a aceitação plena e sem reservas dos Termos e Condições de Uso destas Bibliotecas Digitais, disponíveis em https://digitalis.uc.pt/pt-pt/termos.

Conforme exposto nos referidos Termos e Condições de Uso, o descarregamento de títulos de acesso restrito requer uma licença válida de autorização devendo o utilizador aceder ao(s) documento(s) a partir de um endereço de IP da instituição detentora da supramencionada licença.

Ao utilizador é apenas permitido o descarregamento para uso pessoal, pelo que o emprego do(s) título(s) descarregado(s) para outro fim, designadamente comercial, carece de autorização do respetivo autor ou editor da obra.

Na medida em que todas as obras da UC Digitalis se encontram protegidas pelo Código do Direito de Autor e Direitos Conexos e demais legislação aplicável, toda a cópia, parcial ou total, deste documento, nos casos em que é legalmente admitida, deverá conter ou fazer-se acompanhar por este aviso.

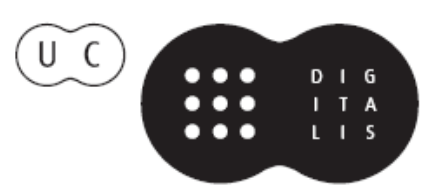


Maria de Fátima Silva

Coordenação

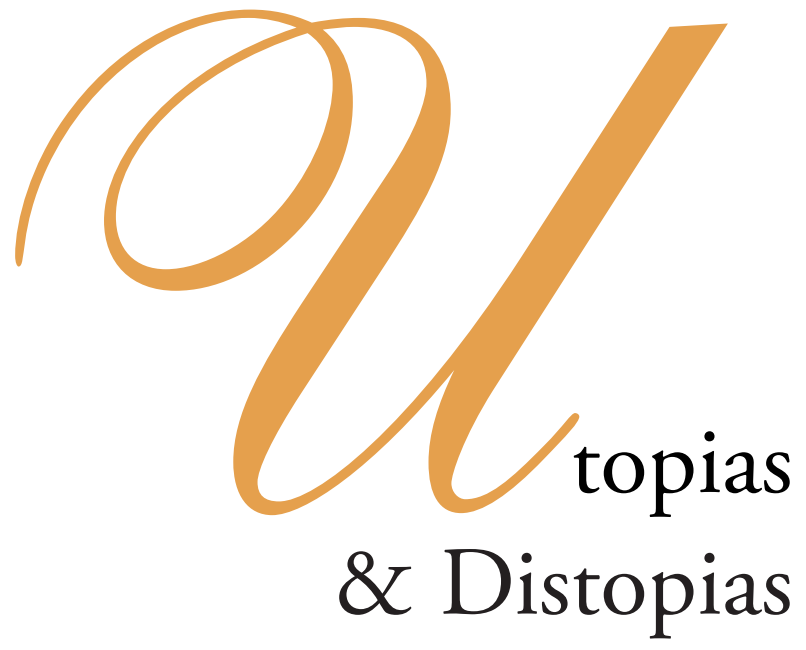




\section{COORDENAÇÃO EDITORIAL \\ Imprensa da Universidade de Coimbra \\ Email: imprensauc@ci.uc.pt \\ URL: http://www.uc.pt/imprensa_uc}

\section{CONCEPÇÃO GRÁFICA}

António Barros

Pré-IMPRESSÃo

Tipografia Lousanense, Lda.

EXECUÇÃO GRÁFICA

Tipografia Lousanense, Lda.

ISBN

978-989-8074-74-4

DEPósito LEGAL

289002/09

OBRA PUBLICADA COM O APOIO DE:

Centro de Estudos Clássicos e Humanísticos

Faculdade de Letras da Universidade de Coimbra

FCT Fundação para a Ciência e a Tecnologia

MINISTÉRIO DA CIÊNCIA, TECNOLOGIA E ENSINO SUPERIOR Portugal 
Maria de Fátima Silva

Coordenação
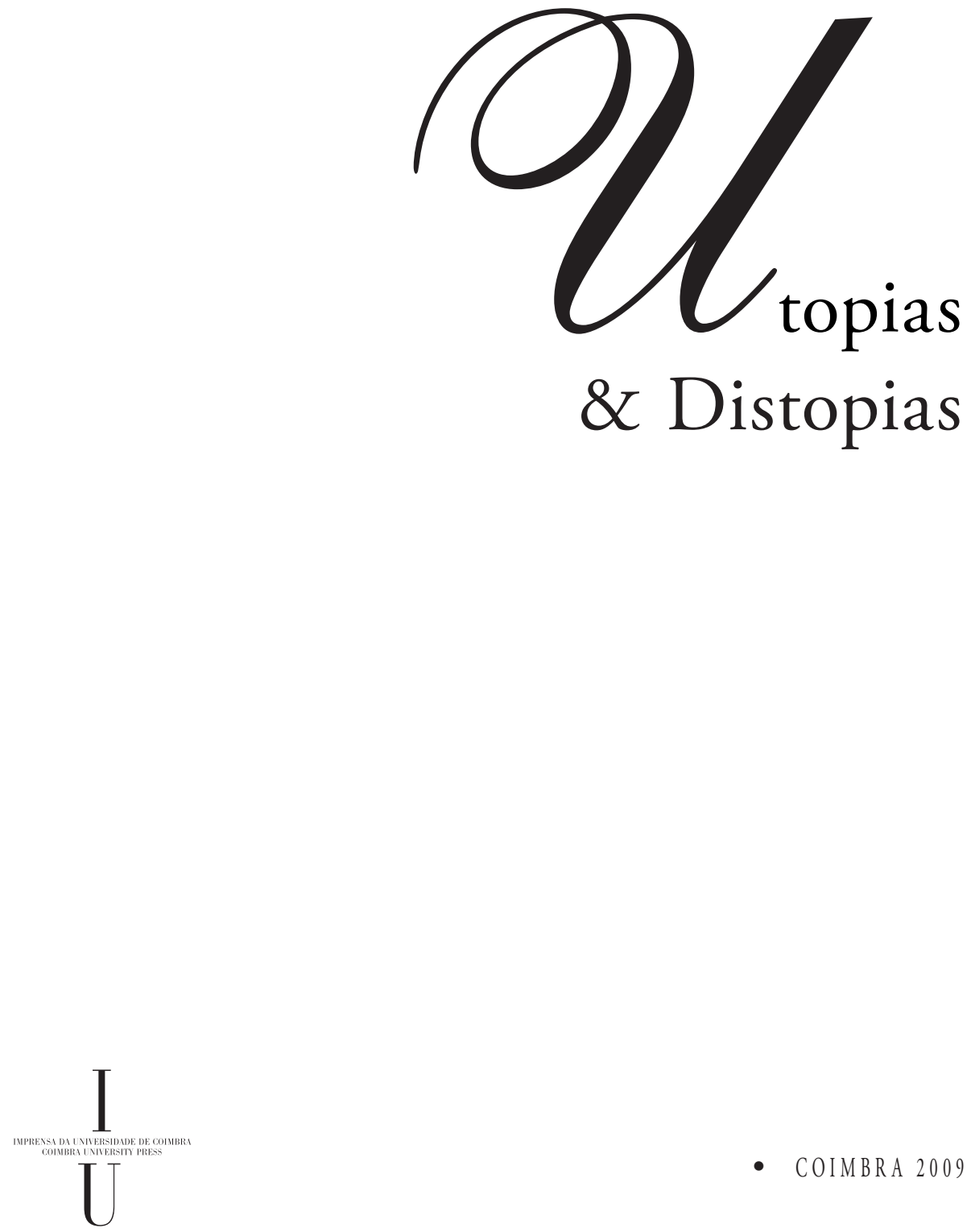

- colmbra 2009 



\section{Carmen Soares}

\section{Bons SELVAGENS E MONSTROS MALDitos EM HeRódoto E EURípides}

O título que escolhi para a minha intervenção neste congresso dedicado à temática das "Utopias e Distopias" contém dois estereótipos recorrentes no imaginário literário universal. A figura do Bom Selvagem - desenvolvida sobretudo por pensadores do séc. XVIII, de entre os quais se destaca Rousseau, e desde entáo aplicada mesmo a referentes cronologicamente anteriores - e a do monstro - amaldiçoado devido aos crimes que comete contra a humanidade - nascem no contexto do confronto cultural que subjaz à formaçáo da identidade (tanto individual, como colectiva). O Homem dito civilizado - e este é o terceiro estereótipo necessário à reflexão sobre a presente matéria - constrói a imagem do seu 'eu' por contraste com aqueles que são o seu reverso. Estes 'outros' são diferentes em relação ao código que rege o 'eu'. Em suma, porque transgridem as normas do 'eu', podemos dizer que os 'outros' se encontram num espaço ou correspondem a uma realidade em que o 'eu' não tem lugar. $\mathrm{Ou}$ seja, entramos no domínio da utopia. Daí que, ao falarmos de Bons Selvagens e de monstros (humanos), estejamos a falar de estereótipos inversos ao estereótipo do 'eu'.

Claro que o 'eu' a que me refiro - a avaliar uma vez mais pelo título desta análise corresponde ao Grego do séc. V a. C. Ao leitor, ouvinte e ou espectador dos textos dramáticos de Eurípides e das "investigaçôes" (historiai) de Heródoto, herdeiro e muitas vezes fautor das empresas de colonização e expansão helénicas para os continentes adjacentes (Ásia e África), a ele não lhe seriam estranhas as alusóes a homens com modos de vida bastante distintos dos seus próprios padrôes culturais, nem táo pouco a seres mais ou menos fantásticos (criações da imaginação, tantas vezes propiciada pelo desconhecimento do 'outro'). A leitura que me proponho fazer parte de um discurso situado pelo seu autor no domínio do real - a prosa de Heródoto - para o universo da ficção, o drama satírico de Eurípides $O$ Ciclope. De entre os diversos povos das Histórias que têm merecido o rótulo de 'selvagens', centrar-me-ei em quatro casos apenas: os Persas (da fase anterior à conquista da Lídia), os Masságetas, os Etíopes de Longa Vida e os Andrófagos ${ }^{1}$.

\footnotetext{
${ }^{1}$ Estudos de referência sobre a temática em apreço são: M. Rosellini et S. Saïd, "Usages des femmes et autres nomoi chez les 'sauvages' d'Hérodote: essai de lecture structurale”, Annali della Scuola Normale Superiori di Pisa 8. 3 (1978), pp. 949-1005; e a colectânea de estudos inteiramente dedicada à presença do Bárbaro em Heródoto: Hérodote et les peuples non grecs. Entretiens sur l’ Antiquité Classique, 35 (Vandoeuvres-Genève, Fondation Hardt, 1990) - editada por O. Reverdin et B. Grange, recolhe artigos de W. Burkert, A. Dihle, P. Briant, J. Harmatta, D. Asheri, M. Lombardo, A. B. Lloyd, S. F. Bondì, G. Nenci.
} 
A razão para me centrar nos relatos que sobre estas etnias oferece Heródoto prende-se com o facto de conterem nítidos itens em comum com a peça euripidiana.

Como se sabe, só se entende, no contexto etnográfico em que nos situamos, a noçáo traduzida pelo adjectivo 'selvagem', se a relacionarmos com o termo correlato 'civilizado'. Ou seja, a identidade daquilo que é 'selvagem' define-se como reflexo inverso do que é 'civilizado' e vice-versa. Os marcadores de identidade fundamentais são o modo de vida, o regime alimentar, o vestuário e o código de valores. Assim, como veremos nos exemplos tirados do texto do historiador de Halicarnasso, o nomadismo, uma alimentação frugal (baseada em produtos naturais, não sujeitos à intervenção de técnicas de confecção elaboradas), um guarda roupa despojado, o conhecimento de algumas normas de convívio social (como a hospitalidade), o valor atribuído a determinados bens (como o ouro e o bronze) e o desconhecimento de princípios basilares da vida em comunidade (como a justiça e a lei) constituem os traços gerais da caracterização do estereótipo do Selvagem. Dentro deste perfil genérico, é ainda possível distinguir os Bons Selvagens dos Monstros Malditos. A distinção baseia-se em que os primeiros representam, para o Homem dito civilizado, um estádio de vida primitivo, caracterizado pelo desconhecimento das comodidades que as conquistas das artes e da técnica trouxeram, mas em que prevalecem valores como: a verdade, a honestidade e o desapego do bem mais valioso para as gentes desenvolvidas, o ouro. Já por Monstros Malditos entende-se aqueles que não se limitam a ignorar princípios basilares da vida em sociedade, mas que, sobretudo, atentam contra eles (praticando, pex., o canibalismo).

Comecemos pelo primeiro tipo. Embora figurem nas Histórias na qualidade de principais oponentes dos Gregos, os Persas não podem ser considerados exclusivamente como representantes do Bárbaro civilizado. Antes de terem conquistado as terras da Lídia, processo que os poria em contacto com a sofisticação e o luxo dos súbditos de Creso, os Persas integravam a vasta galeria dos povos bárbaros primitivos. Marcadores evidentes dessa identidade eram o vestuário e a alimentação. Desconhecedores da técnica da tecelagem, cobriam-se com peles de animais, embora estas já tivessem sido sujeitas à preparação que permite ao autor determinar que o material usado na confecção das típicas calças e restante indumentária era o couro (1. 71. 2). Habitantes de uma terra pobre, de solo bastante pedregoso, desconheciam uma das principais conquistas da agricultura e emblema maior da vida civilizada, a produção do vinho. Habituados a beber água, ignoravam ainda outras 'delícias' (agathá) gastronómicas, de que se destacam os figos (1. 71. 3).

A situação haveria de mudar e os Persas acabariam por representar para os Masságetas o papel que agora cabia aos Lídios. Por ocasião da investida de Ciro contra os territórios dominados pela rainha Tómiris, o rei persa aplica a estratégia de conquista sugerida pelo seu vassalo Creso. Um contingente mais débil de tropas persas é deixado no acampamento, servindo de presa fácil aos Masságetas. No entanto, uma batalha tão rápida e fácil escondia um isco que haveria de inverter o seguimento das operaçôes. O lauto banquete encontrado no acampamento persa seria a perdição das tropas chefiadas pelo príncipe masságeta. O cerne da desgraça radicou, pois, na transgressão dos hábitos próprios. Ou seja, a sua condição de vida nómada fazia deles um povo desconhecedor da agricultura, habituado a comer os animais que criava em rebanhos e os peixes que o grande Araxes oferecia. Por bebida apenas conheciam o leite 
(1. 216. 3-4). Recorrendo ao engano, estratagema desonesto que Tómiris não se coibirá de denunciar (1. 212. 3), Ciro, sob a forma de banquete, oferece ao inimigo a sua sentença de morte ou de prisão. Sucumbindo à tentação das delícias (agathá) - carne em abundância, vinho estreme e toda a espécie de iguarias - os Masságetas, fartos e embriagados, tornam-se presa fácil para os homens de Ciro. Primando por usar sempre um discurso aberto e verdadeiro, a rainha ultrajada denunciará a forma desonesta de actuar do adversário, que recorre como arma de combate não à bravura, mas à astúcia de servir aos inimigos um 'veneno' (phármakos): o vinho. O que se demonstra através deste quadro é que o consumo de vinho puro, um excesso mesmo para os Gregos que o bebiam diluído em água, constitui uma transgressão que pode penalizar o transgressor de duas maneiras: levando-o à morte ou à perda de liberdade.

Estereótipo do Bom Selvagem é, sem dúvida, o uso banal que conferem ao ouro, a mais preciosa das matérias primas segundo os padróes civilizados. A abundância mineira dos solos nesta matéria justifica semelhante banalização. Daí que dos Masságetas Heródoto escreva que usam o ouro para o fabrico de todo o tipo de peças de armamento e de arreios dos cavalos (1.215). Este estatuto de material comum partilham-no com o bronze, também ele abundante na região.

Porém, apesar de ser uma matéria prima comum, o ouro para os Masságetas tem uma utilização nobre. Usam-no no fabrico de instrumentos para a mais prestigiante das actividades, a guerra, e, ao que se depreende do uso do verbo kosméo ('adornar', cf. 1. 215. 1), reconhecem-lhe um valor distintivo. No entanto as Histórias oferecem um exemplo de um povo para quem o tão cobiçado metal náo representa o mínimo valor (seja ele económico ou social). Trata-se dos Etíopes de Longa Vida, o estereótipo mais completo do Bom Selvagem na obra herodotiana. O passo que dá conta do confronto do padrão de civilidade com o seu reverso corresponde a um cenário de hospitalidade. Ao contrário do episódio do massacre e captura das tropas masságetas, em que o banquete de alguma forma poderia ser entendido como um falso "presente de hospitalidade", no encontro entre os embaixadores do persa Cambises e as gentes que este queria conquistar, não há relato de uma refeição de boas vindas. Contudo os presentes enviados pelo xenos ao seu anfitriáo, a apreciaçáo que este lhes tece e as 'maravilhas' que da sua terra lhe mostra denunciam, de forma inequívoca, um estereótipo de vida simples e paradisíaca (3. 20-24). Sinónimo do estádio primitivo em que se encontram os Etíopes é o desconhecimento das técnicas de produção do vinho, do pão, dos tecidos e dos perfumes. Note-se, no entanto, que o Bárbaro não civilizado reage de forma diversa a essas quatro novidades. A primeira (o vinho) atraía a sua curiosidade (3. 22. 3) - reacção que, como vimos pelos exemplos anteriores e pelos que se seguirão, é comum aos ditos "selvagens". A produção de cereais, base da agricultura de subsistência dos povos sedentarizados, não surte um efeito idêntico. Muito pelo contrário! Se é de frutos que a terra produz que o Persa se alimenta, o que ele come não passa de 'estrume' (3. 22. 4). Não é, pois, de admirar que a sua longevidade se fique pelos oitenta anos, média modesta, quando comparada com os cento e vinte anos dos Etíopes ${ }^{2}$. Ainda sem sair da rubrica

2 A longevidade proverbial do povo etíope, por sua vez, ficar-se-ia a dever ao facto de se banharem nas águas de uma fonte com propriedades especiais (3. 23. 2-3). 
da alimentação estereotipada do "selvagem", repare-se que também os Etíopes se incluem entre os "comedores de carne" e "bebedores de leite" (3. 23. 1). Há a acrescentar a este perfil uma nota de idealização. De facto essa gente gozava do privilégio fantástico de possuir um prado que todos os dias lhe oferecia espontaneamente refeiçóes prontas a comer, a chamada Mesa do Sol (3. 118). Segundo os nativos, opinião de que Heródoto se afasta, esta oferenda seria produzida durante a noite pela própria terra, maravilha que os aproxima de um modelo de vida paradisíaco.

Voltando aos presentes de hospitalidade, a veste tingida de púrpura e o perfume (3. 22. 2-3), cujos processos de fabrico são apresentados ao Etíope, náo lhe merecem qualquer crédito, apelidando-os a ambos de 'falsos' (dolerá), bem como aos homens que os produziam (antrópous doleroús). Quanto à explicação de que as jóias oferecidas (um colar de ouro e pulseiras) serviam de ornamento, isto é, de símbolos de prestígio, a reacção que suscita é de incompreensão. $\mathrm{O}$ rei etíope, senhor de uma terra rica em ouro (3.114) e para quem esse metal era usado no fabrico das correntes dos prisioneiros, sorri, sem esconder uma certa nota de superioridade, pois, como escreve Heródoto, convencido de que eram grilhetas, declarou que os Etíopes as tinham bem mais sólidas que aquela (3. 22. 2). Entendida pelos estudiosos modernos como uma perspectiva fantasiosa de Heródoto sobre a riqueza da Etiópia, esta ideia deve ser lida como mais um estereótipo, resultante da associação dos territórios dos Bárbaros a fontes auríferas inesgotáveis.

O quadro de Bons Selvagens, exemplares de um éden perdido, completa-se com a referência à beleza e perfeição física ímpares dos Etíopes, repetidamente apresentados como os mais altos e belos exemplares da raça humana (3. 20. 1; 3. 114). Importa ainda assinalar que os locais de visita escolhidos pelo anfitriáo etíope para mostrar aos embaixadores do rei persa são a prisão e os túmulos do seu povo. Esta informação ser-nos-á útil para a análise d' $O$ Ciclope, uma vez que aí voltaremos a encontrar o aprisionamento e a morte como motivos associados à recepçáo feita pela figura do Selvagem aos seus hóspedes.

Antes, porém, de passarmos a focalizar a nossa atenção na peça euripidiana, há que considerar o povo que nas Histórias recebe a mais expressiva condenação. Em causa estão os Andrófagos, de quem se diz que: de entre todos os homens são os que possuem os mais selvagens costumes (agriótata...êthea, 4. 106). O que faz deles o estereótipo da selvajaria monstruosa é, como indica o próprio etnónimo, o canibalismo. A semelhante crime contra a humanidade somam-se duas faltas igualmente pesadas à luz dos padróes de vida em comunidades organizadas: a inexistência da justiça (a dike) e da lei (o nomos). É da conjugação destes três aspectos que resulta o estereótipo do monstro maldito, que encontramos protagonizado por Polifemo no drama satírico de Eurípides ${ }^{3}$.

Como é do conhecimento geral, o mais antigo registo literário que possuímos da fabula do gigante de um só olho, particular apreciador de carne humana, tem lugar no Livro IX da Odisseia (vv. 105-566). Não vou, no âmbito desta comunicação, entrar em assuntos que outros e eu própria já tratámos noutras ocasióes - como, pex., a

\footnotetext{
3 Outro marcador da identidade 'selvagem' deste povo consiste no modo de vida nómada, comum aos já referidos Masságetas.
} 
relação de dívida e inovação que se pode estabelecer entre a história do drama e a da épica. Limitar-me-ei a considerar em que medida o Ciclope dá corpo a marcadores de identidade próprios do estereótipo do Selvagem, tanto na sua vertente idílica (a do Bom Selvagem) como na transgressora (a do Monstro Maldito).

A raça dos Ciclopes caracteriza-se por aspectos que, como vimos anteriormente a propósito dos Bárbaros primitivos de Heródoto, definem o perfil do indivíduo não civilizado. Ou seja: são nómadas, o que implica um total desconhecimento da organização em cidades e, consequentemente, a inexistência de qualquer regime político; não praticam a agricultura, aludida na referência ao cultivo dos cereais e ao fabrico do vinho; alimentam-se, tal como qualquer selvagem típico, de carne (dos rebanhos e da caça) e têm por bebida o leite; a sua indumentária são peles de animais (v. 330). Recai ainda sobre eles o estigma da bestialidade, uma vez que praticam a antropofagia e que não partilham do código de leis humanas universais: como são a hospitalidade, a súplica e a veneração pela divindade.

Não obstante este enquadramento estereotipado, ao Ciclope de Eurípides não se aplica tout court o rótulo de selvagem. Na verdade, a originalidade do dramaturgo consiste, conforme procurarei demonstrar, em fazer dele uma figura paradoxal e complexa, um misto de besta, bárbaro e homem civilizado. Um ser que é capaz de comer homens só pode ser uma fera (therós, v. 659), que em vez de garganta tem goelas (v. 215) e que, mesmo entregando-se a uma actividade humana, como é a pastorícia, continua a merecer o epíteto de pastor selvagem (melobóta...agrobáta, vv. 53-54). Aliás, essa mesma imagem de animal é a que subjaz à mentira que Sileno, o pai dos Sátiros e intendente da gruta de Polifemo, conta ao seu senhor. Sabedores de quem é o dono do antro onde encontraram os tão necessários víveres, Ulisses e os companheiros teriam ameaçado aprisionar o Ciclope à maneira do que se faz às feras, acorrentando-o a uma coleira (v. 235). A prova mais forte da sua desumanidade reside, precisamente, em atentar, de forma gratuita, contra a vida humana. Polifemo possui uma boca andrófaga (gnáthon...androbrôta, v. 93), cuja voracidade sacia procedendo a sacrifícios humanos (vv. 241-249), actuação que lhe merece o epíteto de devorador de hóspedes (xenodaitumónos, v. 610; xenodaita, v. 658). Daí que o rei de Ítaca lhe chame fera odiosa aos deuses (v. 602).

Apesar de todas estas conotaçôes com as feras, o protagonista da peça, o gigante de um só olho, é apelidado de homem (cf. andrós, v. 605). Escrita por um Grego, para o público grego, a peça encena o confronto entre o modo de vida civilizado e a total subversão de/ou ignorância relativamente a esse sistema. Recorrendo à dialéctica, arte do discurso tão cara aos Sofistas, Eurípides constrói um quadro ímpar de contraposiçáo entre o padrão cultural heleno, defendido por Ulisses (vv. 285-312), e o seu oposto, a barbárie, encarnada em Polifemo (vv. 316-346). O Ciclope rebate todos os princípios estruturantes do modelo de vida civilizado, enunciados por Ulisses: o respeito pelos deuses (eusébeia), a justiça (dike), a súplica (bikêteia) e a hospitalidade (xenia). Desde o prólogo de abertura do drama, o Ciclope vem qualificado de 'sacrílego' (adj. anósios, v. 26) e 'ímpio' (adj. dussebús, v. 30), atributos perfeitamente ajustados à sua pessoa, conforme se depreende do sobranceria com que troça do deus supremo do panteão grego. $\mathrm{Na}$ verdade, não lhe inspira medo um deus que se manifesta por meio de fenómenos climatéricos. Da chuva protege-o o tecto da sua gruta, do frio, as peles de animais com que cobre o corpo e, quanto ao trovão, manifestaçáo 
exclusiva de Zeus tonitroante, rivaliza com ele por meio do ribombar dos seus traques. Se não acredita no pai dos deuses, é, pois, natural que atente contra as instituiçóes humanas que estão sob o seu patrocínio: a philia, a xenia e a hikêteia. Lá que Ulisses e os Gregos tenham defendido os locais sagrados de Poséidon, seu pai, náo lhe desperta qualquer sentimento de retribuição. Dominado pelo seu profundo individualismo, o Ciclope revela-se indiferente a qualquer princípio de solidariedade e interajuda, atitudes estimuladas pela philia. Também os costumes comuns aos mortais (nómos dè thnêtóis, v. 299) de acolher os suplicantes como hóspedes, provendo às suas carências, merecem o total alheamento do senhor do antro. Aliás, semelhante anomia, vem denunciada com profunda indignação por Ulisses, nos seguintes termos:

É costume entre os mortais - se acreditas no que te digo - acolher os suplicantes maltratados pelo mar, oferecer-lhes presentes de hospitalidade e dar-lhes de vestir; náo é costume encher a pança e a boca com os seus membros cravados em espetos de assar bois - como tu fazes! (vv. 299-303).

O Ciclope, porém, náo se deixa impressionar pelas palavras do visitante indesejado, que classifica de fanfarronices e belos discursos (v. 317). Os seus "deuses" são outros: a riqueza (ploutos), a natureza (physis) e ele próprio. Como se lê em dois passos bastante esclarecedores:

Não sabiam que eu sou um deus e que descendo dos deuses? (v. 231).

Eu não sacrifico a mais ninguém, excepto a mim (aos deuses, não!), à mais ilustre divindade, aqui este estômago. Porque o beber e o comer todos os dias, isso sim, é que é Zeus, para quem tem juizo, não o andar a sofrer! (vv. 334-338).

Em suma, o desprezo pela ordem (nómos) criada pelos homens ${ }^{4}$, revela-o Polifemo nos seguintes aspectos: na supremacia que reconhece ao individualismo sobre a philia ${ }^{5}$; na subversão que pratica do código da hospitalidade (contida no sacrifício dos hóspedes ${ }^{6}$, imolados sobre o altar de uma divindade sacrílega); na arrogância de se auto-denominar deus do antro ${ }^{7}$.

Apesar de tudo isto, a verdade é que Polifemo e o mundo que ele personifica não são passíveis de um rótulo padronizado. A esses traços inegáveis de primitivismo e barbárie juntam-se, de forma mais ou menos discreta, notas claras de sofisticação. Neste âmbito, refira-se a prática da caça e organização social em pirâmide. No caso do Ciclope, senhor de vastos rebanhos, a actividade venatória não responde a exigências básicas de subsistência. A caça não surge, pois, como um imperativo decorrente da necessidade,

\footnotetext{
${ }^{4}$ Cf. vv. 338-340: Quanto àqueles que fizeram as leis para embelezar a vida dos homens, que se danem!

5 Cf. vv. 340-341: Pela minha parte, não tenciono parar de fazer bem à minha pessoa - pelo que te vou comer.

${ }^{6}$ Cf. vv. 342-344: Como sou um anfitriāo exemplar, os presentes de hospitalidade que vais receber säo os seguintes: fogo, a água de meu pai e este caldeiräo, que, repleto de pedaços da tua carne, a fará ferver.

7 Cf. vv. 345-346: Mas entrem lá p'ra dentro, para a companhia do deus do antro, a fim de, dispostos à volta do altar, me servirem de repasto.
} 
mas sim como um prazer a que se pode entregar um senhor nos seus tempos livres ${ }^{8}$. Há ainda que não esquecer, no domínio das actividades de subsistência, a criação de gado bovino (alusão ao queijo de vaca, v. 136), sinal evidente da domesticação de animais (também subjacente ao uso de cães na caça, v. 130). Quanto à organização social que o rodeia, Polifemo tem sob as suas ordens uma série de escravos particulares, subalternos com funções bem definidas e distintas. A Sileno, por via da redução de forças que a provecta idade implicaria, estáo confiados os afazeres domésticos, como sejam assegurar a confecção das refeições do amo e manter os seus aposentos, bem como os estábulos dos animais, limpos e arrumados (vv. 29-35). Aos seus filhos, os jovens Sátiros, reservava o Ciclope o pastoreio dos rebanhos pelos montes. Esta rede de serviçais completa-se com uma terceira categoria de mão de obra escrava, os chamados criados do palácio (próspoloi, v. 83). Mais do que o inevitável efeito cómico inerente à associação do antro de Polifemo a um palácio, importa reter que todo este conjunto diversificado de força braçal constitui o suporte social necessário para permitir ao pastor selvagem (como lhe chama o Coro, nos vv. 53-54) dedicar-se à caça.

Em suma: a construção da identidade do grego civilizado do séc. V a. C. só se compreende cabalmente se reflectirmos sobre os seus reversos. A minha proposta consistiu precisamente em fazer incidir as luzes da ribalta em dois ícones maiores e perenes dessa alteridade utópica e distópica: os Bons Selvagens e os Monstros Malditos.

8 Tanto R. SEAFORD (Euripides, Cyclops with introduction and commentary, Oxford, 1984, p. 51) como M. GuARdini ( 'Note per una lettura del Ciclope de Euripide", in L. Finis (ed.), Scena e Apettacolo nell' Antichità. Atti del conzegno Internazionale di studio, Trento, 28-30 marzo 1988, Trento, 1989, p. 212) já notaram na prática da caça por parte do Ciclope um sinal da sua relativa sofisticação. 


\section{Série}

\section{Documentos}

Imprensa da Universidade de Coimbra

Coimbra University Press

2009

- $\mathrm{U}$

C • 